\title{
Early-life socioeconomic circumstances explain health differences in old age, but not their evolution over time
}

\author{
Boris Cheval, ${ }^{\oplus 1,2}$ Dan Orsholits, ${ }^{1}$ Stefan Sieber, ${ }^{1}$ Silvia Stringhini, ${ }^{3}$ \\ Delphine Courvoisier, ${ }^{1,2}$ Matthias Kliegel, ${ }^{1,4}$ Matthieu P Boisgontier, ${ }^{\circ}$ \\ Stephane Cullati, ${ }^{1,2}$
}

- Additional material is published online only. To view please visit the journal online (http://dx.doi.org/10.1136/ jech-2019-212110)

\section{${ }^{1}$ Swiss NCCR 'LIVES -}

Overcoming Vulnerability: Life Course Perspectives', University of Geneva, Geneva, Switzerland ${ }^{2}$ Department of General Internal Medicine, Rehabilitation and Geriatrics, University of Geneva, Geneva, Switzerland

${ }^{3}$ Institute of Social and Preventive Medicine, University Hospital of Lausanne, Lausanne, Switzerland

${ }^{4}$ Center for the Interdisciplinary Study of Gerontology and Vulnerability, University of Geneva, Geneva, Switzerland ${ }^{5}$ Physical Therapy, UBC Hospital, Vancouver, British Columbia, Canada

Correspondence to Boris Cheval, Swiss NCCR "LIVES - Overcoming Vulnerability: Life Course Perspectives", University of Geneva, Geneva 1205, Switzerland; boris.cheval@ unige.ch

Received 11 January 2019 Revised 14 March 2019 Accepted 19 March 2019 Published Online First 9 April 2019
ABSTRACT

Background Early-life socioeconomic circumstances (SEC) are associated with health in old age. However, epidemiological evidences on the influence of these early-life risk factors on trajectories of healthy ageing are inconsistent, preventing drawing solid conclusion about their potential influence. Here, to fill this knowledge gap, we used a statistical approach adapted to estimating change over time and an outcome-wide epidemiology approach to investigate whether early-life SEC were associated with the level of and rate of decline of physical, cognitive and emotional functioning over time. Methods We used data on more than 23000 adults in older age from the Survey of Health, Ageing and Retirement in Europe, a 12-year large-scale longitudinal study with repeated measurements of multiple health indicators of the same participants over time (2004 -2015, assessments every 2 years). Confounder-adjusted linear growth curve models were used to examine the associations of early-life SEC with the evolution of muscle strength, lung function, cognitive function, depressive symptoms and well-being over time.

Results We consistently found an association between early-life SEC and the mean levels of all health indicators at age 63.5 , with a critical role played by the cultural aspect of disadvantage. These associations were only partly explained by adult-life SEC factors. By contrast, evidences supporting an association between early-life SEC and the rate of change in health indicators were weak and inconsistent.

Conclusions Early-life SEC are associated with health in old age, but not with trajectories of healthy ageing. Conceptual models in life course research should consider the possibility of a limited influence of early-life SEC on healthy ageing trajectories.

\section{INTRODUCTION}

In the context of an ageing population, ${ }^{1}$ it is important to better understand the factors involved in (un) healthy ageing trajectories. It is now established that adult health and disease are related to early-life experiences, ${ }^{2}$ including socioeconomic circumstances (SEC). ${ }^{3}$ From an epidemiological viewpoint, the distinction between level and change in health is crucial because health in old age is expected to result from both the maximum health attained during early adult life but also from the rate of decline over ageing. ${ }^{45}$ To understand potential mechanisms linking early-life SEC and health in older age, various conceptual models in life course research have been formulated such as the Strachan-Sheikh model, the latency model, the pathway model and the cumulative model..$^{5-7}$ The latency and the revised Strachan-Sheikh models suggest that exposures to risk factors during early-life influence not only the level of health attained (eg, lower cognitive or physical functioning) but also the rate of health decline (eg, faster loss of cognitive and physical functioning). The pathway model assumes that early-life conditions determines whether individuals follow trajectories that are more or less beneficial for their health. The cumulative model argues that health status in older age is determined by the degree of exposure to adverse conditions, with events experienced in early life playing a critical role. Although the hypothesised mechanisms differ between these models, they all suggest that events encountered in early life, including socioeconomic ones, potentially influence both the level and the rate of decline of health in older age.

Nowadays, large-scale longitudinal population studies on health and ageing have become ubiquitous, allowing researchers to examine the influence of risk factors on the level of health and individual rate of change in health. Several studies suggest a harmful effect of poor early-life SEC on the level of multiple health indicators, including muscle strength, respiratory function, disability, sleep, self-reported health, frailty, cognitive function or depressive symptoms. ${ }^{8-14}$ However, evidence on the effects of early-life SEC on age-related decline in health outcomes is inconsistent. Some studies suggest that early-life SEC influence the rate of health decline (although this may depend on gender or welfare regimes), ${ }^{10} 1213$ whereas other studies revealed no effects. ${ }^{8} 91114$ Thus, whether early-life SEC are associated with the evolution of health in later life is still unclear.

This lack of consistency may result from various factors. First, the previous studies either used a unidimensional measure of early-life SEC (eg, father's occupational position $)^{15}$ or combined different subdimensions of early-life SEC (eg, material and cultural aspects of disadvantage), ${ }^{8} 913$ which may have biassed the associations observed. Second, most previous studies only focused on one health outcome. Yet, the associations between early-life SEC and health may vary depending 
on the dimension of health assessed (eg, physical, cognitive, emotional). ${ }^{16}$ Third, very few studies have assessed whether the associations between early-life SEC and health outcomes are independent from other early-life events likely to co-occur, such as adverse childhood experiences or childhood health problems. ${ }^{17}$ Finally, the statistical approach used in previous studies was not particularly suited to accurately model change over time. Some studies relied on a two-wave design,${ }^{15}$ which is poorly suited for estimating change as it cannot shape each individual's growth trajectory and cannot distinguish true change from measurement error. ${ }^{18}$ Other studies, using more than two occasions of measurement, often adopted an accelerated longitudinal design to model the evolution of health. ${ }^{89}{ }^{19}$ For example, in the study by Ericsson $e t ~ a l,{ }^{19}$ individuals were assessed on nine occasions in 3 years intervals (spanning 28 years), and the model estimated the overall growth trajectories from 50 to 100 years. This analytical strategy, which is useful in providing an overall evolution over a large age range without the need to wait for a longer follow-up, comes at the cost of artificially increasing the noise when estimating the rate of decline over ageing.

To fill this knowledge gap, we investigated, using an analytical strategy suited for estimating change and an outcome-wide epidemiology approach, whether early-life SEC were associated with rate of change over time of various health indicators. We investigated physical (muscle strength and lung function), cognitive (delayed recall and verbal fluency) and emotional (depressive symptoms and well-being) functioning. To further understand the potential long-lasting impact of early-life SEC, we also examined whether the associations were explained by adult-life SEC factors; specifically, level of education, main occupational position during adult life and satisfaction with household income. We hypothesised that disadvantaged early-life SEC are associated with a lower level of health in old age (H1) and potentially with a steeper health decline (H2). In line with the cumulative and pathway models, we further hypothesised that these associations are partially explained by adult-life SEC (H3).

\section{METHODS}

\section{Study population and design}

Data were retrieved from Survey of Health, Ageing and Retirement in Europe (SHARE), a longitudinal European (12 years; 2004-2015; 6 waves of data collected every 2 years) database of individuals aged 50 or older. ${ }^{20}$ Muscle strength was assessed at each of the six waves, cognitive and emotional functioning in five waves (waves 1, 2, 4, 5 and 6) and lung function at waves 2, 4 and 6. Retrospective life course data including early-life SEC were collected in the third wave. We included data for participants aged 50-96 years, who participated in the third wave and had at least two observations for a given health outcome. For cognitive function, consistent with previous studies, we excluded participants with signs of dementia as indicated by scores greater than two on a time orientation question. Online supplementary materials 1 provides more details on all measures described below.

\section{Measures}

Early-life SEC included four binary indicators reflecting specific SEC of participants at the age of $10 .^{21}$ These indicators were (1) the number of books at home (0-10 vs more books at home), (2) a measure of overcrowding (more vs less than one person per room in the household), (3) the occupational position of the household's main breadwinner (first and second vs higher skills levels of the International Standard Classification of Occupations) and (4) housing quality (absence vs presence of either fixed bath, cold running water supply, hot running water supply, inside toilet or central heating).

\section{Health indicators}

Physical functioning was assessed using two indicators: muscle strength and lung function. Muscle strength was measured twice for both hands using a handheld dynamometer (Smedley, S Dynamometer, TTM, Tokyo, $100 \mathrm{~kg}$ ). The mean of the maximum values obtained for each hand at each wave was used as an indicator of muscle strength, ${ }^{8}$ with higher values indicating higher muscle strength. Lung function was measured twice using a Mini-Wright peak flow meter. ${ }^{22}$ The maximum value of the two measurements was used as the outcome, with higher values indicating better lung function.

Cognitive functioning was measured using two indicators of fluid cognitive functions: delayed recall and verbal fluency. Delayed recall was assessed with the 10 -word delayed recall test. ${ }^{23}$ Verbal fluency was assessed using the verbal fluency test. ${ }^{24}$ In these two tasks, a higher number of words given indicated a higher level of cognitive function.

Emotional functioning was assessed using two indicators: depressive symptoms and well-being. Depressive symptoms were assessed using the European Depression (EURO-D) scale, with higher scores indicating more depressive symptoms. ${ }^{25}$ Well-being was assessed using a short version of a quality of life scale (CASP-19), ${ }^{26}$ with higher score reflecting higher quality of life and well-being.

\section{Adult-life SEC mediators}

The following variables were included as potential adult-life SEC mediators: participants' highest educational attainment, main occupational position during adult life and satisfaction with household income.

\section{Covariates}

The following variables were included for all the health outcomes: childhood health problems, birth cohort, attrition and country of residence. Additionally, height was included for muscle strength and lung function. 89

\section{Statistical analysis}

To account for the nested structure of the data (ie, multiple observations within a single individual), mixed-effects models were used. ${ }^{27}$ The random structure encompassed random intercepts for participants and random linear slopes for waves at the level of participants. These random slopes estimated each participant's growth trajectory over the waves of the study (ie, a maximum of 12 years). Moreover, mixed models do not require an equal number of observations from all participants. Therefore, participants with missing observations were included in these models. Analyses were stratified by gender as previous studies have shown potential differences in disease development between women and men over the life course. ${ }^{28}$

Model 1 examined the level and change in the six health indicators separately as a function of the four early-life SEC indicators (number of books, overcrowding, occupational position of the household's main breadwinner and housing quality), adjusting for prior confounders. Age at baseline was centred at the sample's mean (63.5 years), and time at the first measurement occasion for each outcome (wave 2 for peak expiratory flow and wave 1 for all the other health indicators). To properly control for the confounding influence of age at baseline on the rate of change in the health indicators across waves, models included interaction terms between early-life SEC and age at baseline, as well 
Table 1 Participants' characteristics by gender at baseline

\begin{tabular}{|c|c|c|c|c|}
\hline & Men & & Women & \\
\hline \multicolumn{5}{|l|}{ Health indicators } \\
\hline Muscle strength $\left(\mathrm{kg} / \mathrm{m}^{2}\right)$ (intercept; SD) & 44.5 & 10.0 & 27.3 & 7.1 \\
\hline Linear effect of time & -0.96 & $<0.001$ & -0.67 & $<0.001$ \\
\hline Quadratic effect of time & -0.04 & $<0.001$ & -0.01 & 0.551 \\
\hline Peak expiratory flow (L/min)(intercept; SD) & 437.8 & 159.9 & 300.2 & 124.2 \\
\hline Linear effect of time & -5.82 & $<0.001$ & -2.14 & 0.106 \\
\hline Quadratic effect of time & -1.15 & 0.003 & -1.30 & $<0.001$ \\
\hline Cognition. delayed recall (intercept; SD) & 3.4 & 1.9 & 3.8 & 2.0 \\
\hline Linear effect of time & 0.16 & $<0.001$ & 0.12 & $<0.001$ \\
\hline Quadratic effect of time & -0.03 & $<0.001$ & -0.03 & $<0.001$ \\
\hline Cognition. Verbal fluency (intercept; SD) & 19.6 & 7.1 & 19.2 & 7.2 \\
\hline Linear effect of time & -0.37 & $<0.001$ & -0.37 & $<0.001$ \\
\hline Quadratic effect of time & 0.02 & 0.146 & 0.02 & 0.026 \\
\hline Depression (intercept; SD) & 1.7 & 1.9 & 2.7 & 2.3 \\
\hline Linear effect of time & 0.05 & 0.003 & 0.02 & 0.315 \\
\hline Quadratic effect of time & 0.01 & 0.006 & 0.01 & 0.005 \\
\hline Well-being (intercept; SD) & 37.9 & 5.7 & 37.0 & 6.3 \\
\hline Linear effect of time & 0.14 & 0.006 & 00.04 & 0.349 \\
\hline Quadratic effect of time & -0.04 & $<0.001$ & -0.02 & 0.047 \\
\hline \multicolumn{5}{|l|}{ Early-life SEC } \\
\hline \multicolumn{5}{|l|}{ No of book } \\
\hline Less than 10 & 4600 & $44.087 \%$ & 5453 & $42.2 \%$ \\
\hline More than 10 & 5834 & $55.913 \%$ & 7457 & $57.8 \%$ \\
\hline \multicolumn{5}{|l|}{ Occupational position of the main breadwinner } \\
\hline Low skills & 9053 & $86.8 \%$ & 11236 & $87.0 \%$ \\
\hline High skills & 1381 & $13.2 \%$ & 1674 & $13.0 \%$ \\
\hline \multicolumn{5}{|l|}{ Overcrowding (ref. no) } \\
\hline Yes & 7596 & $72.8 \%$ & 9568 & $74.1 \%$ \\
\hline No & 2838 & $27.2 \%$ & 3342 & $25.9 \%$ \\
\hline \multicolumn{5}{|l|}{ Housing quality (ref. high) } \\
\hline Low quality & 2914 & $27.928 \%$ & 3575 & $27.7 \%$ \\
\hline High quality & 7520 & $72.072 \%$ & 9335 & $72.3 \%$ \\
\hline \multicolumn{5}{|l|}{ Adult-life SEC } \\
\hline \multicolumn{5}{|l|}{ Education } \\
\hline Primary & 2638 & $25.3 \%$ & 4199 & $32.5 \%$ \\
\hline Secondary & 5322 & $51.0 \%$ & 6472 & $50.1 \%$ \\
\hline Tertiary & 2474 & $23.7 \%$ & 2242 & $17.4 \%$ \\
\hline \multicolumn{5}{|l|}{ Main ocupational position } \\
\hline Low skill & 7069 & $67.7 \%$ & 8998 & $69.7 \%$ \\
\hline High skill & 3284 & $31.5 \%$ & 2152 & $16.7 \%$ \\
\hline Never worked & 81 & $0.8 \%$ & 1763 & $13.6 \%$ \\
\hline \multicolumn{5}{|l|}{ Satisfaction with Income } \\
\hline With great difficulty & 915 & $8.8 \%$ & 1431 & $11.1 \%$ \\
\hline With some difficulty & 2106 & $20.2 \%$ & 2877 & $22.3 \%$ \\
\hline Fairly easily & 3241 & $31.1 \%$ & 3980 & $30.8 \%$ \\
\hline Easily & 4172 & $39.9 \%$ & 4625 & $35.8 \%$ \\
\hline \multicolumn{5}{|l|}{ Covariates } \\
\hline \multicolumn{5}{|l|}{ Childhood health problems } \\
\hline Yes & 2727 & $26.1 \%$ & 3239 & $25.1 \%$ \\
\hline No & 7707 & $73.9 \%$ & 9671 & $74.9 \%$ \\
\hline \multicolumn{5}{|l|}{ Adverse childhood experiences } \\
\hline Yes & 2257 & $21.6 \%$ & 2716 & $21.0 \%$ \\
\hline
\end{tabular}




\begin{tabular}{|c|c|c|c|c|}
\hline & Men & & Women & \\
\hline No & 8177 & $78.4 \%$ & 10194 & $79.0 \%$ \\
\hline Age at baseline (years), SD & 62.5 & 8.8 & 61.9 & 9.3 \\
\hline \multicolumn{5}{|l|}{ Countries } \\
\hline Belgium & 1129 & $10.8 \%$ & 1346 & $10.4 \%$ \\
\hline Austria & 325 & $3.1 \%$ & 465 & $3.6 \%$ \\
\hline Denmark & 886 & $8.5 \%$ & 1046 & $8.1 \%$ \\
\hline France & 874 & $8.4 \%$ & 1124 & $8.7 \%$ \\
\hline Germany & 770 & $7.4 \%$ & 859 & $6.7 \%$ \\
\hline Greece & 1125 & $10.8 \%$ & 1344 & $10.4 \%$ \\
\hline Italy & 1003 & $9.6 \%$ & 1195 & $9.3 \%$ \\
\hline Netherlands & 855 & $8.2 \%$ & 1015 & $7.9 \%$ \\
\hline Spain & 726 & $6.9 \%$ & 964 & $7.5 \%$ \\
\hline Sweden & 732 & $7.0 \%$ & 911 & $7.1 \%$ \\
\hline Switzerland & 496 & $4 . \%$ & 641 & $5.0 \%$ \\
\hline Czech Republic & 647 & $6.2 \%$ & 886 & $6.9 \%$ \\
\hline Ireland & 200 & $1.9 \%$ & 252 & $1.9 \%$ \\
\hline Poland & 666 & $6.4 \%$ & 865 & $6.7 \%$ \\
\hline \multicolumn{5}{|l|}{ Birth cohort } \\
\hline After 1945 & 4402 & $42.2 \%$ & 5883 & $45.6 \%$ \\
\hline between 1939 and 1945 & 2568 & $24.6 \%$ & 2945 & $22.8 \%$ \\
\hline between 1929 and 1938 & 2557 & $24.5 \%$ & 2886 & $22.3 \%$ \\
\hline between 1919 and 1928 & 907 & $8.7 \%$ & 1199 & $9.3 \%$ \\
\hline \multicolumn{5}{|l|}{ Attrition } \\
\hline No drop-out & 7234 & $69.3 \%$ & 9528 & $73.8 \%$ \\
\hline Drop-out & 2159 & $20.7 \%$ & 2559 & $19.8 \%$ \\
\hline Death & 1041 & $10.0 \%$ & 826 & $6.4 \%$ \\
\hline
\end{tabular}

The baseline characteristics for early-life SEC and covariates are based on the participants included the model testing for muscle strength (ie, the highest sample size). The coefficients associated with the linear and quadratic effects of time were obtained from models including only time and time squared as fixed effects, as well as a random intercept for participants and random linear slopes for waves at the level of participants.

SEC, socioeconomic circumstances.

as between time (linear and quadratic) and age at baseline. ${ }^{29} \mathrm{~A}$ quadratic effect of time was included to account for potential accelerated rate of change of the health indicators across waves. To test whether early-life SEC moderated health indicators' rate of decline over time, Model 1 included interaction terms between early-life SEC and linear and quadratic time; an interaction would indicate that the rate of health indicators decline differs across early-life SEC subgroups. In model 2, the three adult-life SEC indicators (ie, education, main occupational position and satisfaction with household financial situation) were added to model 1. Model 2 also included interaction terms between adult-life SEC and linear and quadratic time. Additionally, for exploratory purposes, three-way interactions between early-life SEC, time (linear and quadratic) and age at baseline were added to model 2. A statistically significant interaction would indicate that the effects of early-life SEC on the rate of change in health over time differ as a function of participants' age. Statistical analyses were performed using $\mathrm{R}$, and the lme4 and lmerTest packages. ${ }^{30-32}$

\section{RESULTS}

\section{Descriptive results}

Table 1 shows participants' baseline characteristics stratified by gender for the largest sample size included in the analysis (ie, muscle strength): 23344 participants (12 910 women, 97507 observations).

\section{Associations of early-life SEC with the mean levels and change of health indicators}

The models that were fitted to the data to examine the level and change in the six health indicators as a function of early-life SEC are presented in tables 2 and 3 .

In model 1, results revealed that the mean level at age 63.5 (intercept) of all health indicators was associated with at least one of the four indicators of early-life SEC in both men and women (rows 4-7 of tables 2 and 3). Specifically, the number of books (row 4) was associated with the mean level of all health indicators, with the exception of peak expiratory flow $(p=0.087)$ among women. In women, occupational position of the main breadwinner (row 5) was associated with the mean levels of cognitive and emotional, but not physical functioning. In men, this early-life SEC indicator was associated with cognitive and physical, but not emotional functioning. However, the association with physical functioning was positive, thereby revealing that compared with men who had highly skilled main breadwinners, people who had low-skilled main breadwinners had a higher level of muscle strength in older age. Overcrowding (row 6) was associated with one indicator of cognitive (verbal fluency) and emotional (depressive symptoms) functioning in both men and women. Housing quality (row 7) was associated with both indicators of cognitive functioning and with one indicator of physical 


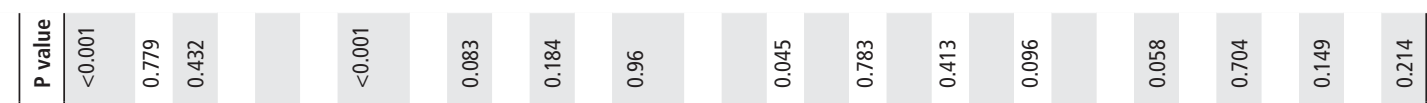

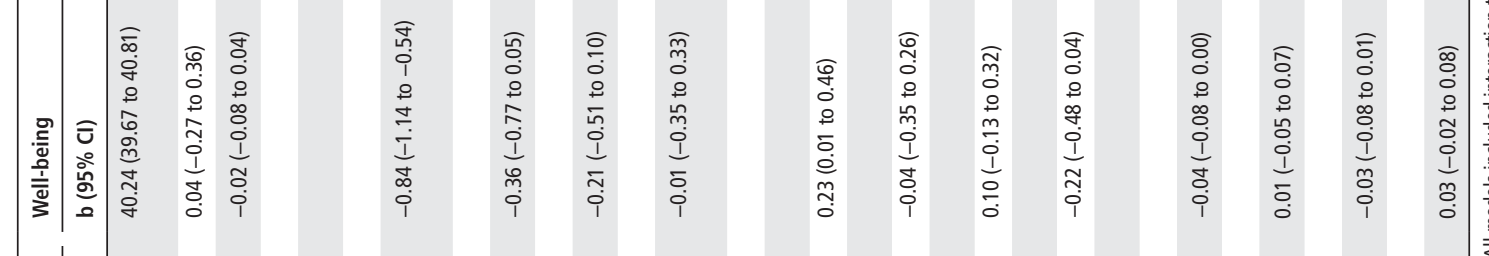

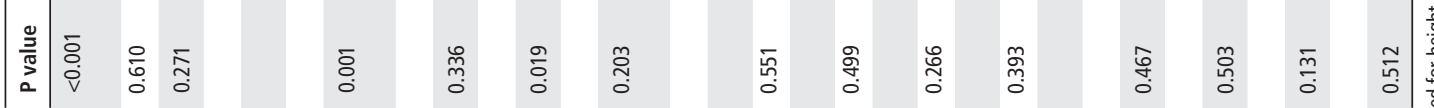

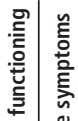

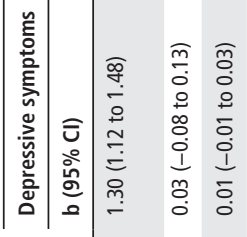

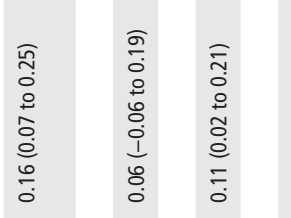

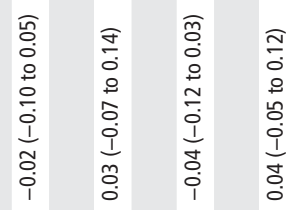

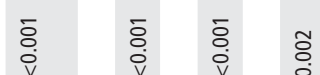

:

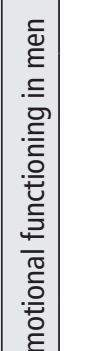

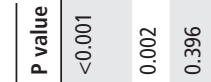

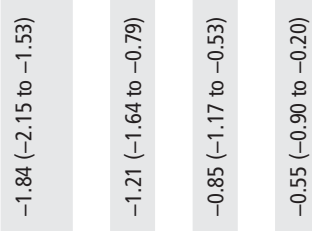

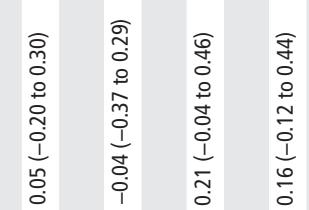

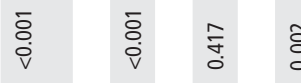

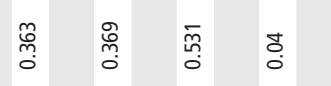

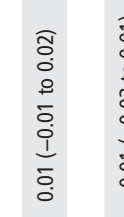

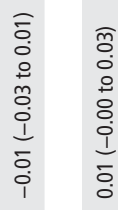

高

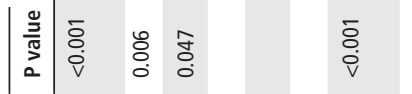

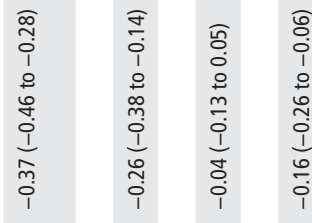

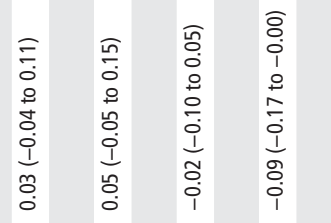

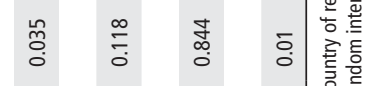

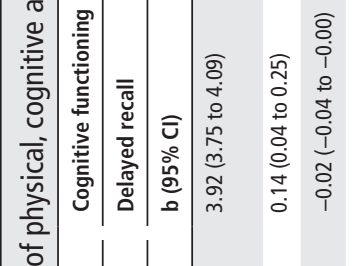

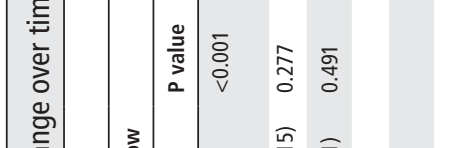

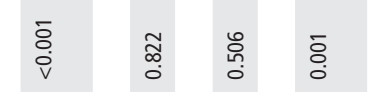

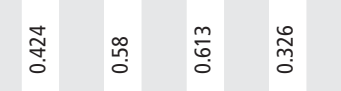

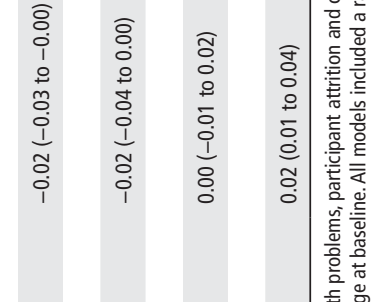

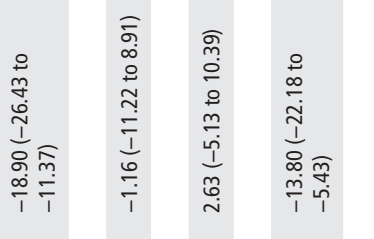

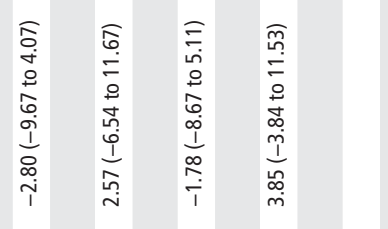

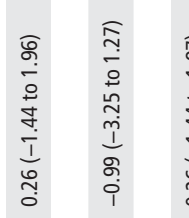

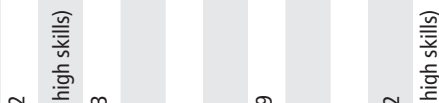

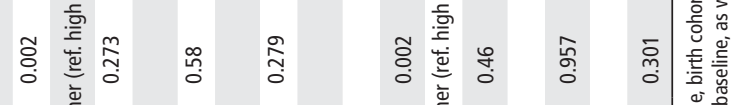

妾

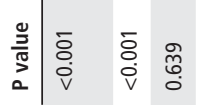

ป

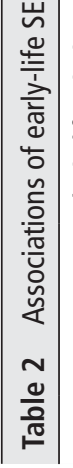

爱

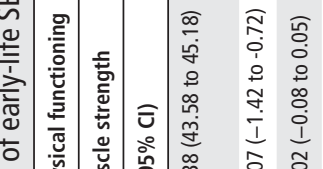

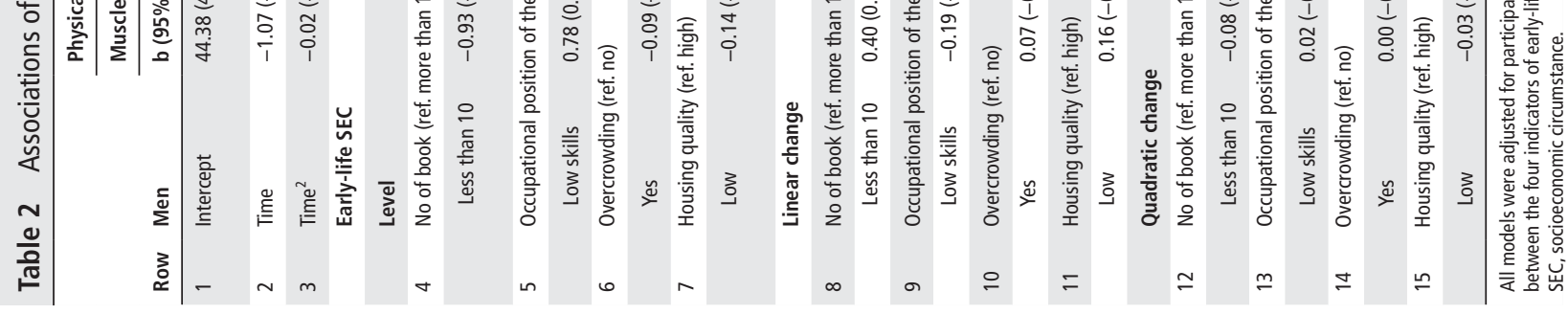

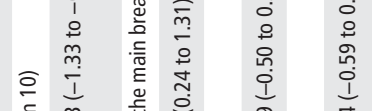

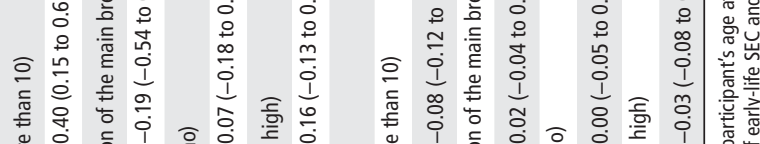

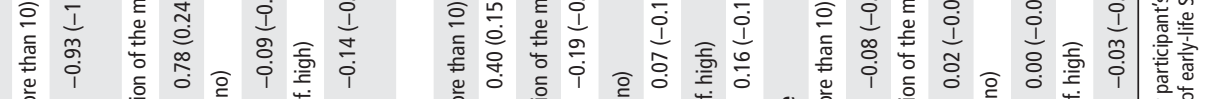




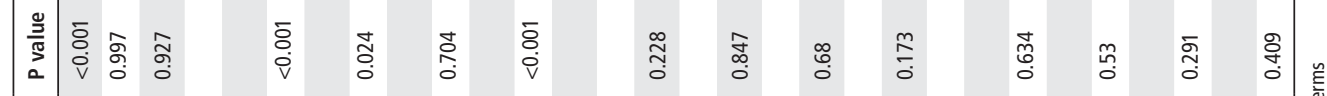

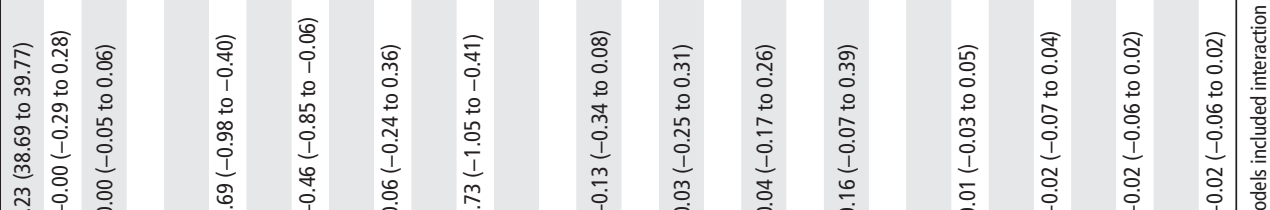

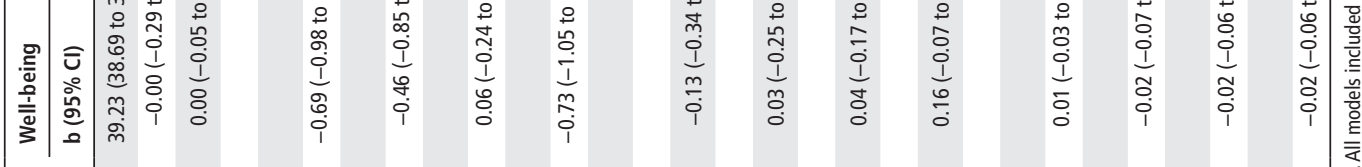

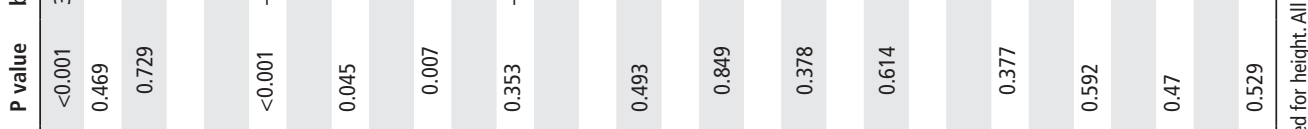

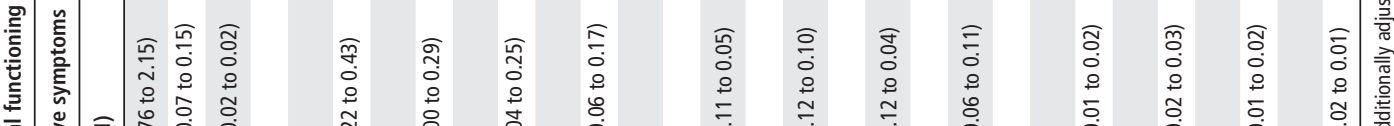

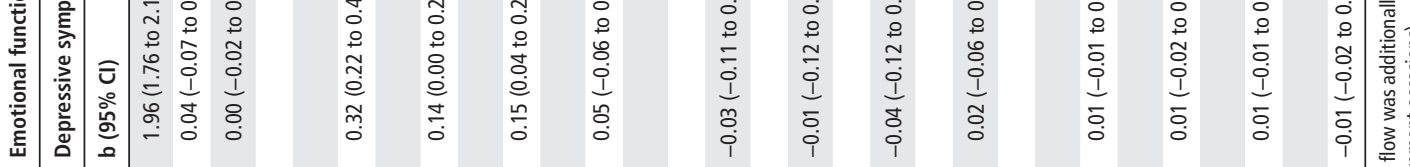
言

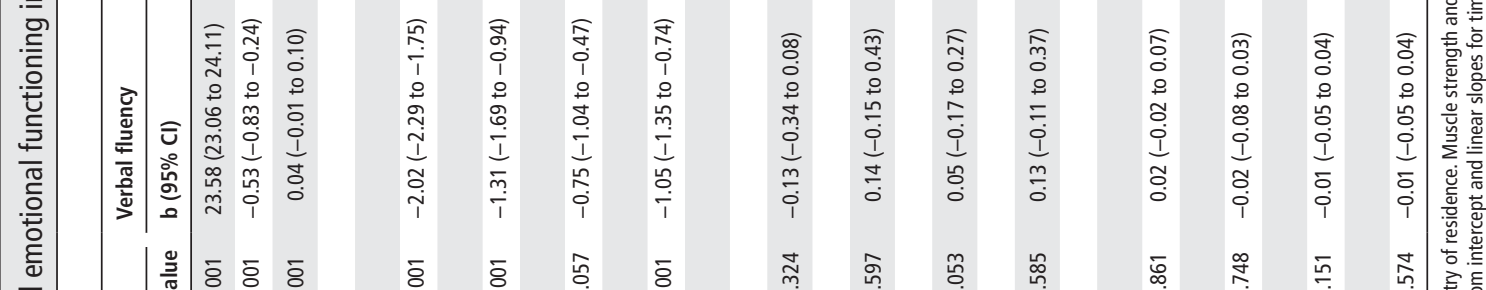

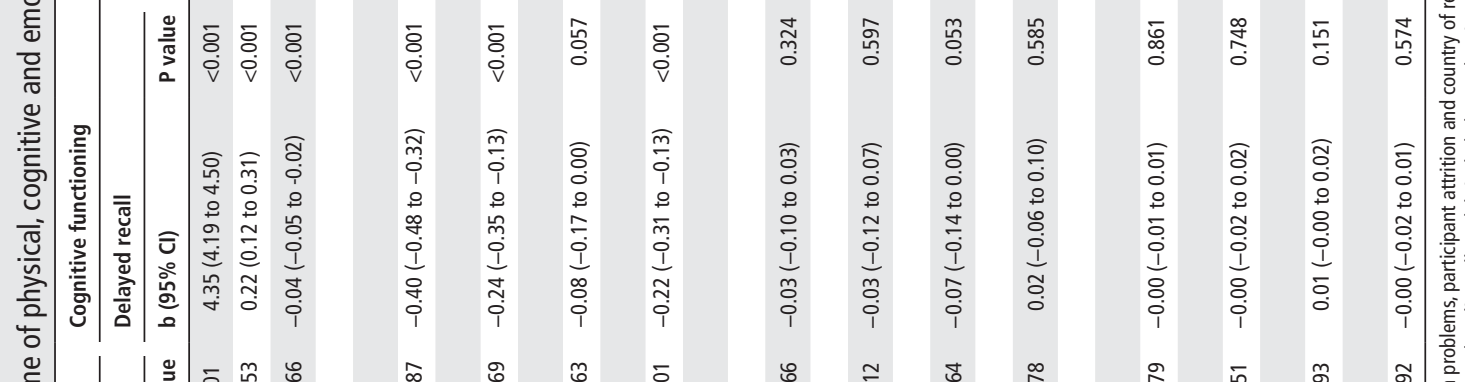

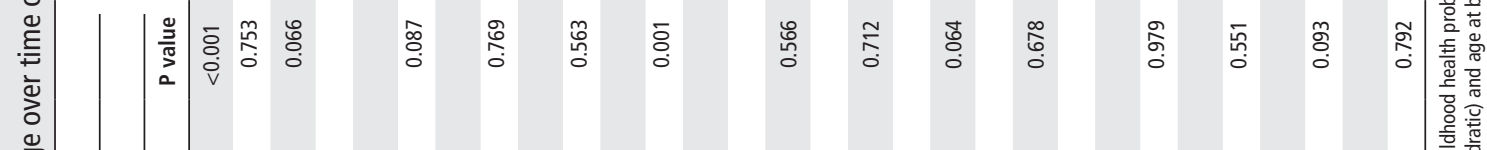

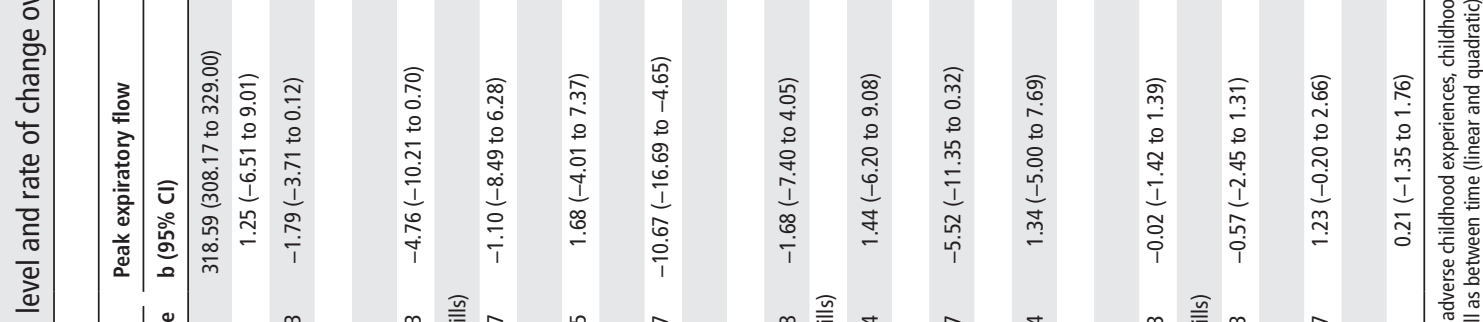

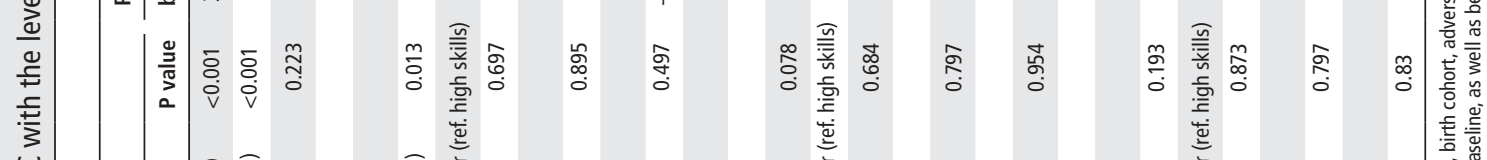

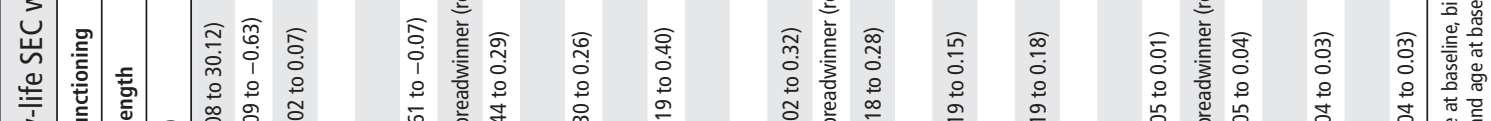

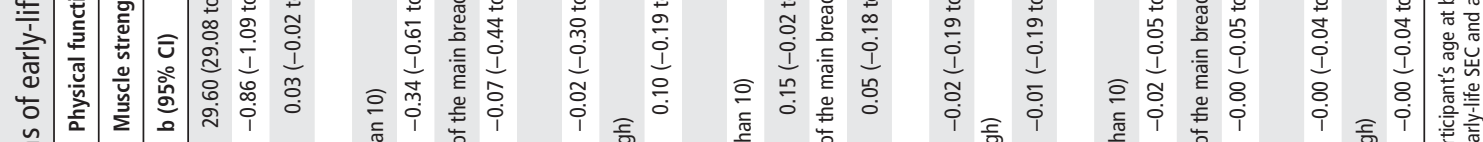

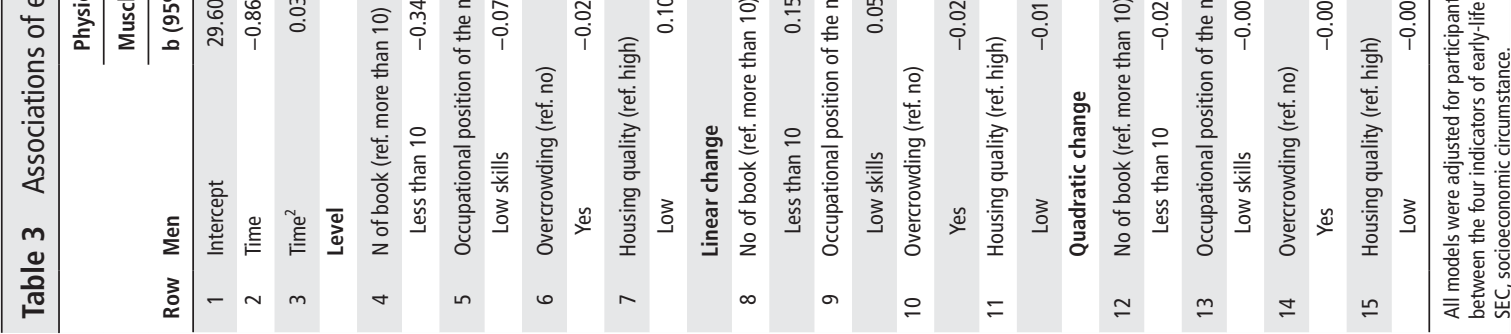


functioning (peak expiratory flow) in both men and women. For women, housing quality was also associated with one indicator of emotional functioning (well-being). These differences in levels were reduced but remained significant overall when adult-life SEC were added to the models, suggesting that the relationships between early-life SEC and the level of health in older age were partly explained by adult-life SEC (online supplementary tables $\mathrm{S} 1$ ).

The four indicators of early-life SEC were not consistently associated with change in all health indicators (rows 8-15 of tables 1 and 2). Specifically, for women, only two marginal associations (row 10) emerged between overcrowding and peak expiratory flow $(\mathrm{p}=0.064)$ and delayed recall $(\mathrm{p}=0.053)$, with a stronger linear decline in these health outcomes for women who lived in an overcrowded household. For men, the number of books (row 8 (linear) and row 12 (quadratic)) was associated with changes in one indicator of physical (muscle strength), cognitive (delayed recall) and emotional (well-being) functioning. Decline in these health outcomes was, compared with men who had a high number of book at home during childhood, significantly accelerated (although the faster decline was only marginal for well-being, $\mathrm{p}=0.058$ ). Moreover, housing quality (row 11 (linear) and row 15 (quadratic)) was only associated with changes in one indicator of cognition functioning (delayed recall). Decline in delayed recall was, compared with men who had poor housing quality during childhood, significantly accelerated in men who had high housing quality. The few associations between the indicators of early-life SEC and the rate of change were also slightly attenuated, indicating that the relationships between early-life SEC and the rate of change in health were partly explained by adult-life SEC (online supplementary tables S2).

Finally, results of the exploratory analyses revealed that participants' age at baseline moderated some of the effects of early-life SEC on the rate of change of health. Specifically, as they get older, muscle strength showed an accelerated decline in men who had poor housing quality during childhood and who had low-skilled main breadwinners. For women, as they get older, results showed an accelerated decline in peak expiratory flow for those who had a low number of books at home during childhood. Moreover, the linear decline in delayed recall, verbal fluency and well-being was more pronounced in women who lived in an overcrowded household. Yet, overcrowding also decelerated the decline in verbal fluency and well-being as women get older.

\section{DISCUSSION}

\section{Main findings}

This large longitudinal European study was conducted to investigate whether early-life SEC are associated with the level and rate of change of various health indicators. Our results confirm that indicators of early-life SEC are associated with the mean levels of physical (muscle strength and peak expiratory flow), cognitive (delayed recall and verbal fluency) and emotional dimensions of health (depression and well-being) (H1). These findings are in line with previous studies demonstrating that, compared with individuals with advantaged early-life SEC, individuals who experienced disadvantaged early-life SEC show lower levels of physical capability, ${ }^{8} 33$ respiratory health, ${ }^{94}$ cognitive function, ${ }^{35}{ }^{36}$ as well as higher levels of depressive symptoms ${ }^{37} 38$ and disability. ${ }^{10} 3940$ However, this study extends previous literature by examining different aspects of early-life disadvantage. Crucially, our results reveal that one indicator of the cultural aspect of disadvantage, namely the number of books, has a wide influence that affected the three dimensions of health. By contrast, the material aspects of disadvantage seem to have more circumscribed effects.

Our results, however, did not support a consistent association between the early-life SEC indicators and the rate of change of the health outcomes (H2). Hence, our study does not fully support the conceptual models in life course research-the latency model, pathway model, cumulative model and Strachan-Sheikh models-arguing a potential link between earlylife SEC and health trajectories in older age. Yet, the absence of consistent effects of early-life SEC across various health outcomes using an adapted analytic strategy to estimate change is a new contribution that may aid in better understanding and delineating the potential range of influences of early-life socioeconomic risk factors on health in older age.

Finally, our results showed that associations between indicators of early-life SEC and the mean levels of health were partly mediated by socioeconomic conditions-level of education, main occupational position during adult life and satisfaction with household income-throughout the life course. The few and inconsistent associations between early-life SEC and the rate of change in health indicators were also attenuated. These findings are consistent with previous studies showing that adultlife SEC do not completely mediate the effect of early-life SEC on health in old age, ${ }^{89} 35$ but also contrast with other studies showing that adult-life SEC fully explain the association between early-life and health in older age (presumably because in these last studies the measures of early-life and adult-life SEC are more related than in the current study). ${ }^{41} 42$

\section{Conceptual models and potential mechanisms}

Our study provides partial support for often-applied conceptual models in life course research: the latency, pathway, cumulative and revised Strachan-Sheikh models. Our findings corroborate the view that the aetiology of health in older age is the result of multiple exposures encountered across the life course, with a critical role played by events arising in early life. ${ }^{5}$ For example, the observation that the effects of early-life SEC and health outcomes are partly explained by adult-life SEC is in line with the pathway and cumulative models.

Crucially, the aetiology of a particular disease may be linked to specific dimensions of early-life disadvantage. For example, poor housing quality, which is associated with mould, dust, dampness or microparticles, is linked with poorer lung function in both men and women, but not with muscular function. Additionally, some disadvantages may have a counterintuitive effect such as men who had low-skilled main breadwinners having higher muscle strength. Finally, it is worth noting that the effects of the different subdimensions of early-life disadvantages on health are gender dependent. For example, the counterintuitive effect of low-skilled main breadwinners on muscle strength is only observed in men. These findings highlight that examining different dimensions of early-life disadvantage may be useful in revealing specific pathways linking early-life conditions to men's and women's health in older age, thus enriching conceptual models employed in life course research. $^{16}$

The direct unmediated effect of early-life SEC on health is consistent with the latency and revised Strachan-Sheikh models suggesting that adverse events arising during sensitive periods of development may have long-lasting negative 
effects on health. For example, studies suggest that experiencing chronic stress during early-life as a consequence of deprivation has a direct negative biological effect on health. ${ }^{43} 44$ These theoretical models also assume that earlylife SEC, by sorting children into specific socioeconomic trajectories (the pathway and cumulative models), or by a direct and sustained effect (the latency and revised Strachan-Sheikh model), should influence health trajectories in older age. However, our findings do not support this view. Nevertheless, this result should not be interpreted as evidence that early-life events have no impact on healthy ageing, but instead should raise awareness about the fact that socioeconomic indicators do not seem to be the best candidates to explain health trajectories.

\section{Strengths and weaknesses}

Among the strengths of the study are the investigation of a wide range of indicators linked to multiple dimensions of health (physical, cognitive and emotional), the assessment of multiple indicators of early-life SEC (material and cultural aspects of disadvantage), the large sample of non-institutionalised older men and women from 14 European countries, and the use of statistical approach particularly suited to model change. However, this study also has some limitations. First, as is inevitable in long-term prospective studies, a selection bias due to attrition cannot be excluded. To minimise this selection bias, all the statistical analyses were adjusted for attrition during SHARE's follow-up. In SHARE, recruitment occurs late in life (after 50) and as such, a selection bias may still persist (healthy survivor bias). However, assuming that those not participating in the survey would be the sickest and thus the most deprived, this may result in an attenuation of all the associations observed. Second, early-life SEC were measured using self-reported retrospective data, which may lead to recall bias. Nevertheless, recall measures of childhood circumstances showed satisfactory validity. ${ }^{45}$

\section{What is already known on this subject}

- Early-life socioeconomic circumstances are associated with health status in old age.

- However, evidence of the effects of early-life circumstances on age-related decline in health outcomes is inconsistent.

\section{What this study adds}

- We showed that the cultural aspect of early-life disadvantage was critical to explain the level of multiple health dimensions at 63.5 of age, including the physical, cognitive and emotional dimensions.

- By contrast, evidence of the contribution of early-life exposures to differences in the decline of the health indicators over time is weak, suggesting that early-life socioeconomic circumstances could hardly explain rate of change in health.

- Conceptual models in life course research should consider the possibility that the influence of early-life socioeconomic circumstances on healthy ageing trajectories is limited.

\section{Conclusion and policy implications}

Early-life SEC are robustly associated with the level of multiple health indicators in old age, even after adjusting for adult-life SEC, with a critical role played by the cultural aspect of disadvantage. By contrast, evidence of the contribution of these early-life exposures to differences in health trajectories over time is weak. Our findings provide support for the longlasting influence of early-life SEC on health in older age. Yet, the conceptual models employed in life course research were only partially supported as early-life SEC were not robustly associated with trajectories of multiple health outcomes. However, the absence of consistent effects of early-life SEC could contribute to shedding light on other critical predictors of healthy ageing trajectories. Conceptual models in life course research should consider the possibility of a limited influence of early-life SEC on healthy ageing trajectories.

Correction notice This article has been corrected since it first published. The 7th author's name has been corrected.

Acknowledgements This paper uses data from SHARE waves 1, 2, 3 (SHARELIFE), 4, 5 and 6 (DOIs: 10.6103/SHARE.w1.600, 10.6103/SHARE.w2.600, 10.6103/SHARE.w3.600, 10.6103/SHARE.w4.600, 10.6103/SHARE.w5.600, 10.6103/SHARE.w6.600), The SHARE data collection was primarily funded by the European Commission through FP5 (QLK6-CT-2001-00360), FP6 (SHARE-I3: RII-CT-2006-062193, COMPARE: CIT5-CT2005-028857, SHARELIFE: CIT4CT-2006-028812) and FP7 (SHARE-PREP: no.211909, SHARE-LEAP: no.227822, SHARE M4: no.261982). Additional funding from the German Ministry of Education and Research, the Max Planck Society for the Advancement of Science, the US National Institute on Aging (U01_AG09740-13S2, P01_AG005842, P01_AG08291, P30_AG12815, R21_AG025169, Y1-AG-4553-01, IAG_BSR06-11, OGHA_04-064, HHSN271201300071C) and from various national funding sources is gratefully acknowledged (see http://www.share-project.org).

Contributors $B C$ designed the analyses. $B C$ analysed the data. $B C$ drafted the manuscript. All authors helped in the interpretation of the data and critically appraised and approved the final version of the manuscript.

Funding This work was supported by the Swiss National Centre of Competence in Research 'LIVES-Overcoming vulnerability: Life course perspectives', which is financed by the Swiss National Science Foundation (SNSF; 51NF40-160590). BC is supported by an Ambizione grant (No: PZOOP1_180040) from the SNSF. The authors are grateful to the SNSF for financial assistance.

Competing interests None declared.

Patient consent for publication Not required.

Ethics approval The relevant local research ethics committees in the participating countries approved SHARE.

Provenance and peer review Not commissioned; externally peer reviewed.

Data sharing statement This SHARE dataset is available at http://www.shareproject.org/data-access.html.

\section{REFERENCES}

1 Mladovsky P, Allin S, Masseria C. Health in the European Union: trends and analysis. WHO Regional Office Europe, 2009.

2 Hanson M, Gluckman P. Developmental origins of noncommunicable disease: population and public health implications. Am J Clin Nutr 2011;94(suppl_6):1754S-8.

3 Poulton R, Caspi A, Milne BJ, et al. Association between children's experience of socioeconomic disadvantage and adult health: a life-course study. Lancet 2002;360:1640-5.

4 Vineis P, Kelly-Irving M, Rappaport S, et al. The biological embedding of socia differences in ageing trajectories. J Epidemiol Community Health 2016;70:111-3.

5 Strachan DP, Sheikh A. A life course approach to respiratory and allergic diseases. In: Kuh D, Ben-Shlomo Y, eds. A life course approach to chronic disease epidemiology. Oxford: Oxford University Press, 2004: 240-59.

6 Hertzman C. The biological embedding of early experience and its effects on health in adulthood. Ann N Y Acad Sci 1999;896:85-95.

7 Ben-Shlomo Y, Kuh D. A life course approach to chronic disease epidemiology: conceptual models, empirical challenges and interdisciplinary perspectives. Int J Epidemiol 2002;31:285-93.

8 Cheval B, Boisgontier MP, Orsholits D, et al. Association of early- and adult-life socioeconomic circumstances with muscle strength in older age. Age Ageing 2018;47:398-407. 
9 Cheval B, Chabert C, Orsholits D, et al. Disadvantaged early-life socioeconomic circumstances are associated with low respiratory function in older age. J Gerontol A Biol Med Sci 2018;381.

10 Landös A, von Arx M, Cheval B, et al. Childhood socioeconomic circumstances and disability trajectories in older men and women: a European cohort study. Eur J Pub Health 2018.

11 Straat vande V, Cheval B, Schmidt RE, et al. Early predictors of impaired sleep: a study on life course socioeconomic conditions and sleeping problems in older adults. Aging Ment Health in press.

12 Sieber S, Cheval B, Orsholits D, et al. Welfare regimes modify the association of disadvantaged adult-life socioeconomic circumstances with self-rated health in old age. Int J Epidemiol 2019;381.

13 Aartsen MJ, Cheval B, Sieber S, et al. Advantaged socioeconomic conditions in childhood are associated with higher cognitive functioning but stronger cognitive decline in older age. PNAS 2019.

14 Van der Linden BWA, Cheval B, Sieber S, et al. Life course socioeconomic conditions and frailty at older ages. J Gerontol B Psychol Sci Soc Sci 2019;63.

15 Ramsay SE, Whincup PH, Lennon LT, et al. Longitudinal associations of socioeconomic position in childhood and adulthood with decline in lung function over 20 years: results from a population-based cohort of British men. Thorax 2011;66:1058-64.

16 Sacker A, Head J, Gimeno D, et al. Social inequality in physical and mental health comorbidity dynamics. Psychosom Med 2009;71:763-70.

17 Cheval B, Chabert C, Sieber S, et al. The association between adverse childhood experiences and muscle strength in older age. Gerontology 2019.

18 Singer JD, Willett JB. A framework for investigating change over time. in applied longitudinal data analysis: modeling change and event occurrence. New York: Oxford University Press, 2003.

19 Ericsson M, Lundholm C, Fors S, et al. Childhood social class and cognitive aging in the Swedish Adoption/Twin study of aging. Proceedings of the National Academy of Sciences 2017;114:7001-6.

20 Börsch-Supan A, Brandt M, Hunkler C, et al. Data resource profile: the survey of health, ageing and retirement in Europe (SHARe). Int J Epidemiol 2013;42:992-1001.

21 Wahrendorf M, Blane D. Does labour market disadvantage help to explain why childhood circumstances are related to quality of life at older ages? Results from share. Aging Ment Health 2015;19:584-94.

22 Wright BM. A miniature Wright peak-flow meter. BMJ 1978;2:1627-8.

23 Harris SJ, Dowson JH. Recall of a 10-word list in the assessment of dementia in the elderly. Br J Psychiatry 1982;141:524-7.

24 Rosen WG. Verbal fluency in aging and dementia. J Clin Exp Neuropsychol 1980;2:135-46.

25 Prince MJ, Reischies F, Beekman ATF, et al. Development of the EURO-D scale - a European Union initiative to compare symptoms of depression in 14 European centres. Br J Psychiatry 1999;174:330-8.

26 Hyde M, Wiggins RD, Higgs P, et al. A measure of quality of life in early old age: the theory, development and properties of a needs satisfaction model (CASP-19). Aging \& Mental Health 2003; 7:186-94.

27 Boisgontier MP, Cheval B. The ANOVA to mixed model transition. Neurosci Biobehav Rev 2016:68:1004-5.
28 Barboza Solís C, Kelly-Irving M, Fantin R, et al. Adverse childhood experiences and physiological wear-and-tear in midlife: findings from the 1958 British birth cohort. Proc Natl Acad Sci USA 2015;112:E738-E46.

29 Keller MC. Gene x environment interaction studies have not properly controlled for potential confounders: the problem and the (simple) solution. Biol Psychiatry 2014;75:18-24.

30 Bates $D$, Mächler M, Bolker B, et al. Fitting linear mixed-effects models using Ime4. 2015 2015;67.

31 R Core Team. R: a language and environment for statistical computing. Vienna, Austria, 2017. Available: https://www.R-project.org/

32 Kuznetsova A, Brockhoff PB, Christensen RHB. ImerTest: tests in linear mixed effects models. R package version 2.0-33, 2016. Available: https://CRAN.R-project.org/ package $=$ ImerTest

33 Caleyachetty R, Hardy R, Cooper R, et al. Modeling exposure to multiple childhood social risk factors and physical capability and common affective symptoms in later life. J Aging Health 2018;30:386-407.

34 Hegewald MJ, Crapo RO. Socioeconomic status and lung function. Chest 2007;132:1608-14.

35 Ericsson M, Lundholm C, Fors S, et al. Childhood social class and cognitive aging in the Swedish Adoption/Twin study of aging. Proc Natl Acad Sci USA 2017;114:7001-6.

36 Kaplan GA, Turrell G, Lynch JW, et al. Childhood socioeconomic position and cognitive function in adulthood. Int J Epidemiol 2001;30:256-63.

37 Angelini V, Howdon DD, Mierau JO, et al. And Late-Adulthood mental health: results from the survey on health, ageing and retirement in Europe. J Gerontol B Psychol Sci Soc Sci 2018.

38 Tani Y, Fujiwara T, Kondo N, et al. Childhood socioeconomic status and onset of depression among Japanese older adults: the JAGES prospective cohort study. Am J Geriatr Psychiatry 2016;24:717-26.

39 Bowen ME, González HM. Childhood socioeconomic position and disability in later life: results of the health and retirement study. Am J Public Health 2010;100:S19 7-\$203.

40 Fujiwara T, Kondo K, Shirai K, et al. Associations of childhood socioeconomic status and adulthood height with functional limitations among Japanese older people: results from the JAGES 2010 project. I Gerontol A Biol Med Sci 2014;69:852-9.

41 Lyu J, Burr JA. Socioeconomic status across the life course and cognitive function among older adults: an examination of the latency, pathways, and accumulation hypotheses. J Aging Health 2016;28:40-67.

42 Stansfeld SA, Clark C, Rodgers B, et al. Childhood and adulthood socioeconomic position and midlife depressive and anxiety disorders. $\mathrm{Br} J$ Psychiatry 2008;192:152-3.

43 Baum A, Garofalo JP, Yali AM. Socioeconomic status and chronic stress. does stress account for Ses effects on health? Ann N Y Acad Sci 1999;896:131-44.

44 Juster R-P, McEwen BS, Lupien SJ. Allostatic load biomarkers of chronic stress and impact on health and cognition. Neurosci Biobehav Rev 2010;35:2-16.

45 Havari E, Mazzonna F. Can we trust older people's statements on their childhood circumstances? Evidence from SHARELIFE. Eur J Popul 2015:31:233-57. 